\title{
ATLETAS DE DIFERENTES MODALIDADES ESPORTIVAS COM COR DA PELE PRETA TÊM MENOR AUTOESTIMA INDEPENDENTEMENTE DE SEU STATUS DE ATLETA
}

\author{
Victor Rodrigues Goulart \\ Universidade do Estado de Santa Catarina, Florianópolis, Santa Catarina, Brasil. \\ Walan Robert Da Silva \\ Universidade do Estado de Santa Catarina, Florianópolis, Santa Catarina, Brasil. \\ Thiago Emannuel Medeiros \\ Universidade do Estado de Santa Catarina, Florianópolis, Santa Catarina, Brasil. \\ Fernando Luiz Cardoso \\ Universidade do Estado de Santa Catarina, Florianópolis, Santa Catarina, Brasil.
}

\begin{abstract}
Resumo
O presente estudo verificou possíveis diferenças na percepção da autoestima em atletas com diferentes cores de pele autorrelatadas. Participaram 256 atletas com 22,1 (dp:4,5) anos de diferentes modalidades esportivas. Utilizou-se o "Questionário de Caracterização dos Atletas" e a "Escala de Autoestima de Rosenberg". Para verificar diferenças nas variáveis, foram utilizados ANOVA e Bonferroni. A maioria dos atletas era composta por brancos, homens, com escolaridade média completa, oriundos do futebol de campo e competiam em nível nacional e internacional. A autoestima foi significativamente menor nos atletas de cor de pele preta. Conclui-se que esses atletas sofrem maior influência depreciativa em sua autoestima, não sendo atenuada pelo seu status positivo de atleta.
\end{abstract}

Palavras-chave: Racismo. Autoestima. Psicologia do Esporte. Preconceito.

\section{ATHLETES OF DIFFERENT SPORTS MODALITIES WITH BLACK SKIN COLOR HAS SELFSTEEM REGARDLESS OF THEIR ATHLETE STATUS}

\begin{abstract}
This studies verified differences on self-esteem perception of athletes with different skin color self-reported. Participated 256 athletes with 22,1 (dp:4,5) years of different sports modalities. Was used the "Characterization Athletes Questionnaire" and "Rosenberg Self-esteem Scale". To verify differences on variables was utilized ANOVA and Bonferroni. The most of the athletes were white, men, complete high school, practitioners soccer and contest national and international competition. Self-esteem was significantly low on black skin athletes. Concluded that this athletes suffer great negative influence on yours self-esteem, not being attenuated by their positive athlete status.
\end{abstract}

Keywords: Racism. Self-esteem. Sport Psychology. Preconception. 


\title{
ATLETAS DE DIFERENTES MODALIDADES DEPORTIVAS CON COLOR DE PIEL NEGRA TIENEN MENOR AUTOESTIMA INDEPENDIENTEMENTE DE SU STATUS DE ATLETA
}

\begin{abstract}
Resumen
El presente estudio verificó posibles diferencias en la percepción de la autoestima en atletas con diferentes colores de piel autoidentificados. Participaron 256 atletas con 22,1 ( $d p:$ 4,5) años de diferentes modalidades deportivas. Se utilizó un "Cuestionario de Caracterización de los Atletas" y la "Escala de Autoestima de Rosenberg". Para verificar las diferencias en las variables se utilizó ANOVA y Bonferroni. La mayoría de los atletas eran blancos, hombres, con escolaridad media completa, oriundos del fútbol de campo y competían a nivel nacional e internacional. La autoestima fue significativamente menor en los atletas de piel negra. Se concluye que esos atletas sufren mayor influencia despreciativa en su autoestima, no siendo atenuada por su status positivo de atleta.
\end{abstract}

Palabras-clave: Racismo. Autoimagem. Psicología del Deporte. Prejuicio

\section{Introdução}

Os fatores psicológicos estão ligados diretamente a um bom ou a um mau desempenho nos esportes (CORRÊA et al., 2002). O despreparo psicológico é um fator determinante para o resultado final insatisfatório nas mais distintas modalidades esportivas (HIROTA; TRAGUETA; VERARDI, 2008). Desse modo, não há como negar a necessidade de se abordar o trabalho psicológico no esporte, principalmente nas diferentes fases de treinamento e nos torneios aos quais serão submetidos os atletas (MOTTA, 2009).

Nesse sentido, observa-se a autoestima como um dos fatores influenciadores para uma boa performance em distintas modalidades esportivas. Segundo Bednar, Wells e Peterson (1995), a autoestima pode ser compreendida como a forma pela qual as pessoas aceitam a si mesmas, valorizam o outro e projetam suas expectativas de vida, sendo também uma mediadora do quanto o sujeito está satisfeito ou insatisfeito em relação às situações vividas, isto é, quando essa manifestação é positiva, geralmente o indivíduo se sente confiante, competente e possuidor de valor pessoal, dispondo de uma boa autoconfiança (HUTZ; ZANO, 2011). Neste trabalho, a autoestima é tratada a partir do conceito de Rosenberg (1965), que a define como um conjunto de emoções e pensamentos a respeito do seu valor e competência, reproduzidos em atitudes positivas ou negativas com relação a si mesmo.

Sabe-se que, para que a autoestima se construa, é necessário que o sujeito reconheça-se como indivíduo e como parte da sociedade em que está inserido (MOYSÉS, 2001). Existem padrões socialmente impostos que determinam maneiras de ser, agir e pensar que são colocadas como um ideal. A partir do momento em que determinado indivíduo foge dos padrões, estará sujeito a ser percebido como diferente, ou pior, como inferior perante os estereótipos sociais (JULIO, 2011). Nos esportes, pode-se citar a mídia como influenciadora na autoestima dos atletas, submetendo-os a processos de exclusão por fatores irrelevantes como sua cor de pele, algo que predominou por muito tempo como uma ideia de superioridade de uma cor de pele/raça sobre a outra (ANDREWS, 1997).

Desse modo, conforme exposto por Cartwright (1950), grupos oprimidos ou estigmatizados como os negros tendem a desenvolver baixas autoavaliações, pois são mantidos e percebidos em baixa consideração por outros. Todavia, ter maior ou menor concentração de melanina no corpo não determina o que o indivíduo é ou deixa de ser. Porém, esse fato só se concretiza a partir da influência do meio, modificando a sua autopercepção, desde o momento em que alguns padrões sociais são rompidos (RABELLO, 2009). 
A partir da ideia de que o meio influencia na percepção de cada indivíduo sobre si, o esporte tornar-se-ia espelho da sociedade, refletindo os aspectos positivos e negativos. Historicamente, o esporte é utilizado de inúmeras formas, realizando funções distintas, que podem ser econômicas, culturais, ideológicas, educacionais, sociais, etc. É utilizado também como ferramenta de exclusão por grupos dominantes que reforçam estereótipos socialmente elaborados. Mesmo com altas habilidades, minorias étnico-raciais são submetidas a processos excludentes do mundo esportivo, segregando-os das consideradas altas classes (GREGÓRIO; MELO, 2015). ${ }^{1}$

Torna-se importante entender a relevância da cor da pele para o autoconhecimento e a autoestima do indivíduo, uma vez que o self é retratado como um produto social cujo conteúdo depende das relações sociais mantidas pelo indivíduo, podendo existir diferenças entre grupos raciais com relação às variedades perceptivas e aos processos cognitivos presentes na autoavaliação de cada indivíduo (GRAY-LITTLE; HAFDAHL, 2000). Dessa forma, o objetivo do presente estudo é verificar se existem diferenças na percepção da autoestima em atletas com diferentes cores de pele autorrelatadas.

\section{Método}

\section{Caracterização da pesquisa}

O presente estudo é caracterizado como um estudo exploratório, transversal, de natureza descritiva, correlacional, já que, através de análises, definições e esclarecimentos, busca delinear um perfil capaz de caracterizar as variáveis envolvidas em um dado fenômeno (GAYA, 2008). Nessa situação, a principal finalidade do estudo é levantar e analisar dados empíricos para avaliar uma possível associação entre cor da pele e autoestima em atletas de diferentes modalidades esportivas controlando seus preditores.

\section{Participantes}

Participaram do estudo 256 atletas, sendo 167 do sexo masculino e 89 do feminino, com média de idade de 22,1 $(d p=4,5)$, praticantes das modalidades de futebol de campo, futsal, voleibol, handebol, basquetebol, atletismo, judô e karatê das cidades de Curitiba-PR, São José dos Pinhais - PR e Florianópolis - SC. A escolha dos participantes da pesquisa foi realizada de forma intencional nos níveis estaduais, federais e internacionais de participação. Os dados aqui utilizados foram extraídos dos bancos do projeto intitulado "Perfil Esportivo e Psicológico de Atletas e Bailarinos", do Laboratório de Gênero, Educação, Sexualidade e Corporeidade (LAGESC), submetido e avaliado pelo Comitê de Ética em Seres Humanos da UDESC, sob o registro 14829113.2.0000.0118.

\section{Procedimentos de coleta de dados}

Em um primeiro momento, foi realizado um contato com os clubes esportivos dos estados de SC e PR que trabalham com formação esportiva. Os clubes que aceitaram participar da pesquisa receberam a visita dos pesquisadores do LAGESC para esclarecimentos quanto à pesquisa junto às comissões técnicas e aos atletas, apresentando o objetivo, a relevância, os procedimentos das coletas de dados, a garantia do total sigilo de identificação na participação da pesquisa, bem como o convite aos atletas para participar.

1. O presente trabalho não contou com apoio financeiro de nenhuma natureza para sua realização. 
Aos atletas que concordaram em participar da pesquisa, foi entregue o Termo de Consentimento Livre e Esclarecido (TCLE), para que fossem assinados por eles ou pelos pais/responsáveis quando o atleta era menor de idade. Após a obtenção dos consentimentos, as avaliações foram realizadas. As coletas de dados ocorreram nas dependências dos locais de treinamento, mediante a entrega do Termo de Consentimento Livre e Esclarecido e Termo de Assentimento devidamente assinados.

A coleta de dados foi realizada a partir da aplicação dos questionários sociodemográficos, de caracterização esportiva e autoestima. A aplicação dos instrumentos acima citados foi realizada em grupo, em um local reservado dentro das dependências do clube. Cada atleta recebeu os instrumentos e respondeu a eles de forma individual, sendo recomendado que não conversassem durante o preenchimento dos questionários. $\mathrm{O}$ pesquisador sempre estava à disposição dos atletas para sanar dúvidas.

\section{Instrumentos}

Questionário de Caracterização dos Atletas

Com o objetivo de caracterizar os participantes, foi elaborado um questionário pelo autor do estudo incluindo informações referentes a sexo, escolaridade, cor da pele, modalidade esportiva praticada e nível das competições de que participa, com a finalidade de diferenciar os grupos.

Escala de autoestima

Para investigar a autoestima dos atletas, a pesquisa utilizou-se da Escala de Autoestima de Rosenberg. A representação da escala é feita através da Figura 1, retratando uma tabela com diversas afirmações sobre a percepção que o indivíduo tem sobre sua vida. A tabela é composta por dez afirmações e detém valores ao lado que variam de " $0=$ Não se aplica"; " $1=$ Aplica-se pouco"; " $2=$ Aplica-se moderadamente"; " $3=$ Aplica-se muito" e " $4=$ Aplica-se totalmente". O atleta deve marcar um "X" sobre o número correspondente ao grau de aplicação de cada afirmação sobre sua vida.

\section{Figura 1}

$* *$ AUTOESTIMA $* *$

$0=$ Discordo Fortemente $; 1=$ Discordo Pouco $; 2=$ Não concordo nem discordo $; 3=$ Concordo Pouco; 4 = Concordo Fortemente.

\begin{tabular}{|c|c|c|c|c|c|}
\hline $\begin{array}{l}01 \text { Sinto que sou uma pessoa de valor, no mínimo, tanto quanto as outras } \\
\text { pessoas. }\end{array}$ & 0 & 1 & 2 & 3 & 4 \\
\hline $02 \mathrm{Eu}$ acho que eu tenho varias boas qualidades & 0 & 1 & 2 & 3 & 4 \\
\hline 03 Levando tudo em conta, eu penso que sou um fracasso. & 0 & 1 & 2 & 3 & \\
\hline $04 \mathrm{Eu}$ acho que sou capaz de fazer coisas tão bem quanto à ma & 0 & 1 & 2 & 3 & \\
\hline $05 \mathrm{Eu}$ acho que eu não tenho muito que me orgulhar & 0 & 1 & 2 & 3 & 4 \\
\hline $06 \mathrm{Eu}$ tenho uma atitude positiva com relação a mim mesmo & 0 & 1 & 2 & 3 & \\
\hline 07 No conjunto, eu estou satisfeito comigo. & 0 & 1 & 2 & 3 & \\
\hline $08 \mathrm{Eu}$ gostaria de poder ter mais respeito por mi & 0 & 1 & 2 & 3 & \\
\hline 09 Às vezes eu me sinto inútil & 0 & 1 & 2 & 3 & \\
\hline 10 Às vezes eu acho que não presto para nad & 0 & & & 3 & \\
\hline
\end{tabular}

Fonte: SBICIGO; BANDEIRA; DELL'AGLIO, 2010. 


\section{Análises dos dados}

Os dados foram tabulados e armazenados no programa Microsoft Excel® e analisados no pacote estatístico SPSS - Statistical Package for Social Sciences (versão 20.0). Foi realizada uma análise descritiva através da frequência simples e de valores de média e desviopadrão, caracterizando os participantes do estudo. Para verificar possíveis diferenças na autoestima dos atletas com relação à cor da pele, foi empregada a Análise de Variância (ANOVA). Posteriormente, utilizou-se a correção de Bonferroni para verificar quais grupos diferiam entre si.

\section{Resultados}

Características sociodemográficas e esportivas

Com relação à caracterização dos participantes, na Tabela 1 observam-se as características sociodemográficas dos participantes e informações associadas a suas respectivas modalidades esportivas. De forma geral, a maioria era formada por brancos, homens, com escolaridade média completa, oriundos do futebol de campo e competiam em nível nacional e internacional.

Tabela 1. Características sociodemográficas e esportivas dos participantes

\begin{tabular}{ccc}
\hline & Variável & $\boldsymbol{n}(\boldsymbol{\%})$ \\
\hline \multirow{2}{*}{ Sexo } & Masculino & $167(65,2)$ \\
& Feminino & $89(34,8)$ \\
Escolaridade & Médio incompleto & $14(5,5)$ \\
& Médio Completo & $64(25,0)$ \\
& Superior incompleto & $104(40,2)$ \\
& Superior completo & $74(28,9)$ \\
Cor da pele & Branca & $150(58,6)$ \\
& Preta & $26(10,2)$ \\
& Amarela & $10(3,9)$ \\
& Parda & $67(26,2)$ \\
& Indígena & $2(0,8)$ \\
& & \\
Mível competitivo & Futebol de campo & $80(31,2)$ \\
& Futsal & $29(11,3)$ \\
& Voleibol & $22(8,5)$ \\
& Handebol & $30(11,7)$ \\
& Basquetebol & $35(13,6)$ \\
& Atletismo & $12(4,6)$ \\
& Judô & $30(11,7)$ \\
& Karatê & $13(5,0)$ \\
& Estadual & $102(39,8)$ \\
& Nacional & $97(37,8)$ \\
& & $57(22,2)$ \\
\hline
\end{tabular}


Tabela 2. Comparação entre cor da pele e o escore de autoestima

\begin{tabular}{|c|c|c|c|c|c|c|c|}
\hline & & & Cor da pele & & & $\mathbf{F}$ & $p$ \\
\hline Itens & $\begin{array}{l}\text { Branca } \\
X(d p)\end{array}$ & $\begin{array}{l}\text { Preta } \\
\text { X(dp) }\end{array}$ & $\begin{array}{l}\text { Amarela } \\
\text { X(dp) }\end{array}$ & $\begin{array}{l}\text { Parda } \\
\text { X(dp) }\end{array}$ & $\begin{array}{l}\text { Indígena } \\
\text { X(dp) }\end{array}$ & & \\
\hline 1 & $3,52(0,78)$ & $3,42(0,64)$ & $4,10(0,69)$ & $3,57(0,76)$ & - & 3,87 & 0,81 \\
\hline 2 & $3,58(0,77)$ & $3,42(0,94)$ & $3,60(0,69)$ & $3,70(0,67)$ & - & 8,1 & 0,52 \\
\hline 3 & $3,37(0,80)$ & $3,42(0,70)$ & $3,20(1,03)$ & $3,36(0,75)$ & $3,50(0,70)$ & 1,62 & 0,95 \\
\hline 4 & $2,97(1,02)$ & $2,96(0,99)$ & $2,70(0,94)$ & $2,76(1,18)$ & $2,50(2,12)$ & 6,05 & 0,65 \\
\hline 5 & $3,17(1,08)$ & $3,35(0,79)$ & $2,40(1,43)$ & $2,82(1,26)$ & - & 2,423 & $0,49 *$ \\
\hline 6 & $2,71(1,14)$ & $2,19(1,05)$ & $3,00(0,94)$ & $2,22(1,21)$ & $2,00(1,41)$ & 3,224 & $0,13 *$ \\
\hline 7 & $3,41(0,68)$ & $3,58(0,57)$ & $3,20(0,78)$ & $3,40(0,71)$ & $3,50(0,70)$ & 6,2 & 0,64 \\
\hline 8 & $3,75(0,53)$ & $3,81(0,40)$ & $3,40(0,96)$ & $3,76(0,46)$ & - & 1,305 & 0,26 \\
\hline 9 & $2,75(1,30)$ & $1,96(1,28)$ & $2,70(0,94)$ & $2,43(1,41)$ & - & 2,838 & $0,25 *$ \\
\hline 10 & $2,74(1,11)$ & $2,35(1,19)$ & $2,80(1,31)$ & $2,49(1,22)$ & $3,00(1,41)$ & 10,6 & 0,37 \\
\hline Escore & 31,9 & 30,4 & 30,6 & 30,5 & 33,5 & 1,18 & 0,31 \\
\hline
\end{tabular}

Nota: $\mathrm{O}$ símbolo $(*)$ indica diferenças significativas $(p: 0,05)$ nos itens da autoestima em relação às classificações de cor da pele. $X$ : média; $(d p)$ : Desvio-padrão.

Fonte: Elaborada pelo autor, 2018.

\section{Autoestima}

Com relação à autoestima dos participantes, na Tabela 2 é possível observar que ocorreram diferenças significativas no que diz respeito à autoestima associada à cor da pele. Nas respostas das perguntas 5 (eu tenho uma atitude positiva em relação a mim mesmo), 6 (no conjunto, eu estou satisfeito comigo mesmo) e 9 (às vezes, eu acho que não presto para nada, pessoas de cor de pele preta e amarela apresentam valores inferiores aos outros grupos étnicos. Com relação ao escore, observa-se diferenciação significativa apenas em indivíduos de cor de pele preta em relação aos demais grupos, na qual estes apresentam uma menor autoestima autoavaliada

\section{Discussão}

Como resultado principal do estudo, verificou-se que sujeitos de cor de pele preta acreditam não ter muito do que se orgulhar quando comparados a outros grupos étnicos. Também se constatou que eles sentem-se mais inúteis e acreditam não ter uma atitude positiva com relação a si próprios. Esses resultados podem ser atribuídos a uma história constituída por preconceito racial, que defendeu por muito tempo a ideia de superioridade de uma raça sobre outra (ANDREWS, 1997).

Apesar da discussão cada vez mais presente na sociedade sobre discriminação racial, ainda ocorrem situações de preconceito, fazendo com que a abordagem em relação ao tema torne-se necessária devido à falta de informações e conhecimentos acerca da realidade em que se encontra grande parte da população negra e dos preconceitos sofridos por ela (DOS SANTOS FILHO, 2016), bem como sobre as origens dessa condição (OLIVEIRA, 2008) no contexto do esporte. Por se tratarem de atletas, esses dados se mostram ainda mais expressivos, pois acredita-se que eles, por terem um status de relevância social - atletas, deveriam sentir-se mais aceitos pelos seus desempenhos esportivos e pela representação de suas comunidades (VAZ, 2010). 
Entretanto, há inúmeros casos de discriminação racial e preconceito dentro dos esportes brasileiros, o que comprova o não cumprimento e respeito do artigo $5^{\circ}$ da Constituição Federal de 1988, a qual versa que: "Todos são iguais perante a lei, sem distinção de qualquer natureza" (BRASIL, 1988). Um exemplo de racismo no contexto do esporte brasileiro trata-se do caso ocorrido com o atleta Mário Lúcio Duarte Costa, mais conhecido como Aranha. De acordo com matéria publicada pelo site Globo Esporte em 2014, e largamente difundida nas redes sociais, o goleiro foi alvo de ofensas racistas na partida entre Santos e Grêmio válida pela Copa do Brasil no mesmo ano. Esses atos levaram o goleiro a pedir a paralisação do jogo, cobrando providências das autoridades da partida. Ao final do jogo, Aranha afirmou que as vaias reforçavam as atitudes preconceituosas tomadas pelos torcedores que o atacaram.

Outro caso de preconceito racial que ocorreu no mundo dos esportes envolveu a seleção brasileira de ginástica artística. Foi relatado pelo site $O$ Globo, em 2017, a publicação de um vídeo em uma rede social em que três ginastas de cor de pele branca fazem piadas de cunho racista com Ângelo Assunção, de cor de pele preta. Isto nos mostra que o preconceito não escolhe um esporte específico e pode se encaixar em diversos setores da sociedade.

Após os episódios, os culpados pelos crimes relataram sentimento de culpa e acabaram por se desculpar publicamente, mas as vítimas tiveram sua condição psicológica afetada, que de fato abala a autoestima. Aranha, em entrevista ao site SporTV no ano de 2017, enalteceu a atitude de poucas pessoas que em jogos atuais demonstraram sensibilidade com o caso de racismo protagonizado pela própria torcida gremista. Declarou também que elas não representam uma maioria. Por fim, afirma que a sociedade necessita semear coisas boas e que gestos como este aos poucos podem fazer a diferença.

Para Gregório e Melo (2015), o preconceito racial dentro do esporte pode manifestarse através das mídias com o reforço de estereótipos, excluindo a individualidade e generalizando o comportamento dos negros e suas características. Exemplo disto são as classificações sociais de modalidades esportivas, que dividem as suas práticas em esportes tidos como finos - golfe, hipismo, natação, automobilismo, polo aquático, tênis, entre outros - e esportes populares, dentre eles o atletismo, os coletivos - futebol, basquetebol, handebol, vôlei -, e principalmente os que retomam o contexto histórico e cultural afrodescendente, como a capoeira.

O fortalecimento do controle social por classes dominantes se dá através das relações que cada uma delas pode manter com seu esporte. A imposição de regras e limites materiais alto custo de equipamentos esportivos, falta de infraestrutura, falta de patrocínios, fatores psicológicos, etc. - são determinantes e dificultam a ascensão das classes mais baixas nas suas modalidades (GREGÓRIO; MELO, 2015).

É possível verificar que, através do esporte, a representatividade negra se deu apenas em modalidades específicas. Uma modesta parte conseguiu ascender socialmente, porém, de uma forma ainda muito restrita, confirmando a segregação desportiva que fortalece as desigualdades sociais atribuídas aos preconceitos (GREGÓRIO; MELO, 2015). Não há como falar de uma sociedade igualitária sem falar de uma educação de qualidade pautada em valores éticos, morais e humanísticos. Os seres humanos se constroem com as experiências e aprendizados, portanto, o meio em que se vive tem grande influência sobre ele (FARIA, 1998).

Como podemos constatar, os resultados nos mostram que a percepção de cor da pele é algo que está diretamente relacionado à autoestima. Deve-se ter consciência dos inúmeros casos que interferem negativamente na vida desses indivíduos, contribuindo para o fortalecimento da discriminação racial e da baixa autoestima. É de suma importância que se interrompa o ciclo histórico do preconceito racial, sendo as escolas um grande fator de intervenção. 
Uma vez que é na escola que começamos a ter nossas primeiras relações sociais, pondo em prática os princípios básicos da cidadania, é de suma importância que seja nela também que comecemos a conhecer a história de um país construído por mãos negras e indígenas. Tendo em vista que os pensamentos racistas deslegitimam o papel do homem negro e sua história no contexto social (CANEN, 2013), faz-se da educação um instrumento de mudança. Desse modo, o papel do professor é de extrema importância na mediação do conhecimento repassado às pessoas, principalmente na infância. Reafirmando sua função de conscientizar sobre qualquer forma de preconceito que venha a assombrar nossa sociedade, molda alunos capazes de transformar o meio em que convivemos.

Infelizmente, nenhum estudo que tivesse produzido dados quantitativos sobre a associação encontrada na presente pesquisa e denunciada em tantas outras teóricas e críticas foi identificado para que pudéssemos melhor discutir os nossos dados inéditos.

\section{Conclusão}

Constatou-se que há uma associação entre a cor da pele e a autoestima em atletas de diferentes modalidades esportivas. De maneira geral, pessoas com cor de pele preta sofrem maior influência depreciativa em sua autoestima, devido à insistência de manifestações preconceituosas.

Uma das limitações para a realização desta pesquisa foi a escassez de estudos que abordassem a temática em questão para a discussão dos resultados quantitativos, uma vez que não foram encontrados estudos semelhantes na literatura para uma comparação entre os dados, nem mesmo dados estatísticos sobre a participação dos negros no esporte nacional.

Apesar de a cor da pele ser um dos critérios que mais se cuida nas pesquisas das Ciências do Movimento Humano no Brasil, quase nenhuma pesquisa faz esse recorte em suas análises de dados. Fica um questionamento dessa ausência de abordagens a possíveis diferenças nos dados coletados em nosso país em relação à diversidade de fenótipos.

Como sugestão para próximos estudos, indica-se a realização de uma abordagem sobre questões étnicas e não somente a cor da pele. Uma vez que a busca incessável pela extinção do racismo ou quaisquer tipos de preconceitos contra negros não acaba aqui. Este trabalho é um alerta para que possamos de alguma forma mudar nossa realidade e conquistar uma sociedade igualitária, afinal, ninguém muda o que não conhece.

\section{Referências}

ANDREWS, G. R. Democracia racial brasileira 1900-1990: um contraponto americano. Estudos Avançados, São Paulo, v. 11, n. 30, p. 95-115, ago. 1997.

ARANHA lê cartaz, agradece a gremista, mas não volta atrás em críticas. SportTV. São Paulo, 17/07/17. Disponível em: <http://sportv.globo.com/site/programas/troca-depasses/noticia/2017/07/aranha-le-cartaz-agradece-gremista-mas-nao-volta-atras-emcriticas.html>. Acesso em: 14 set. 2017.

BEDNAR, R. L.; WELLS, M. G.; PETERSON, S. R. Self-esteem: paradoxes and innovations in clinical theory and practice, n. 2. Washington, D.C.: American Psychological Association, 1995. $433 \mathrm{p}$.

BRASIL. Constituição da República Federativa do Brasil. Brasília, DF: Senado Federal: Centro Gráfico, 1988. 13 p. 
BRITO, C. C.; OLIVEIRA, M. T. Bullying and self-esteem in adolescents from public schools. Jornal de Pediatria, Rio de Janeiro, v. 89, n. 6, p. 601-607, jan. 2013.

BATISTA, A. C.; MELGAÇO DA SILVA JUNIOR, P.; CANEN, A. Em busca de um diálogo entre Plano Nacional de Educação (PNE), formação de professores e multi/interculturalismo. Ensaio: Avaliação e Políticas Públicas em Educação, Rio de Janeiro, v. 21, n. 79, p. 253-267, abr./jun. 2013.

CANEN, A. Refletindo sobre Identidade Negra e Currículo nas Escolas Brasileiras: contribuições do multiculturalismo. Série-Estudos-Periódico do Programa de Pós-Graduação em Educação da UCDB, Campo Grande, n. 15, p. 49-57, jan./jun. 2003.

CARTWRIGHT, D. Emotional dimensions of group life. In: REYMERT, M. L. Feelings and emotions. Nova York: McGraw-Hill, 1950. p. 437-447.

CORREAAI, D. K. D. A. et al. Excelência na produtividade: a performance dos jogadores de futebol profissional. Psicologia: Reflexão e Crítica, Porto Alegre, v. 15, n. 2, p. 447-460, fev. 2002.

DOS SANTOS FILHO, M. C. B. O conceito de genocídio na história brasileira. 2016. 86 f. Dissertação (Mestrado em Ciências Políticas) - Centro Universitário Euroamericano (UNIEURO), Brasília, 2016.

FARIA, A. R. Desenvolvimento da criança e do adolescente segundo Piaget. São Paulo: Ática, 1998.

GAYA, A. Ciências do Movimento Humano: introdução à metodologia da pesquisa. Porto Alegre: Artmed, 2008.

GRAY-LITTLE, B.; HAFDAHL, A. R. Factors influencing racial comparisons of selfesteem: a quantitative review. Psychological Bulletin, Illinois, v. 126, n. 1, p. 26-54 2000.

GREGÓRIO, F.; MELO, B. M. Preconceito racial no esporte nacional. Esporte e Sociedade, São Paulo, v. 10, n. 24, p. 1-31, mar. 2015.

GUILHARDI, H. J. Auto-estima, autoconfiança e responsabilidade. In: BRANDÃO, M. Z. I.; CONTE, F. C. S.; MEZZAROBA, S. M. B. (Org.). Comportamento humano: tudo (ou quase tudo) que você queria saber para viver melhor. Santo André, SP: ESEtec, 2002. 158 p.

HIROTA, V. B.; TRAGUETA, V.; VERARDI, C. E. L. Nível de estresse pré-competitivo em atletas universitárias do sexo feminino praticantes do futsal. Conexões, Campinas, SP, v. 6, ed. esp, p. 487-497, jul. 2008.

HUTZ, C. S.; ZANON, C. Revisão da adaptação, validação e normatização da escala de autoestima de Rosenberg. Avaliação Psicológica, Porto Alegre, v. 10, n. 1, p. 41-49, abr. 2011.

JULIO, A. L. Por uma visão psicossocial da autoestima de negros e negras. Protestantismo em Revista, São Leopoldo, v. 24, p. 62-69, jan./abr. 2011. 
MOTTA, M. M. D. O treinamento técnico-desportivo: um estudo descritivo-exploratório com tenistas adultos federados. 2009. 78 f. Dissertação (Mestrado em Ciências do Movimento Humano) - Escola de Educação Física, UFRGS, Porto Alegre, 2009.

MOYSÉS, L. Auto-estima se constrói passo a passo. Campinas, SP: Papirus, 2001.

OLIVEIRA, A. A participação do atleta negro no esporte: das pistas de atletismo às pistas de Fórmula 1. Revista Digital, Buenos Aires, v. 13, n. 126, nov. 2008. Disponível em: $<$ http://www.efdeportes.com/efd126/a-participacao-do-atleta-negro-no-esporte.htm >. Acesso em: 20 jan. 2018.

RABELLO, E.; PASSOS, J. S. Erikson e a teoria psicossocial do desenvolvimento. v. 16, p. 08-13, 2009. Disponível em: <http://www.josesilveira.com>. Acesso em: 20 jan. 2018.

ROSENBERG, M. Society and the adolescent self-image. Princeton: Princeton University Press, 1965.

SANTOS vence grêmio e tem grande vantagem; Aranha denuncia racismo. Globo Esporte. São Paulo, 28 ago. 2014. Disponível em: <http://globoesporte.globo.com/jogo/copa-do-brasil2014/28-08-2014/gremio-santos.html>. Acesso em: 30 ago. 2017

SBICIGO, J. B.; BANDEIRA, D. R.; DELl'AGLIO, D. D. Escala de Autoestima de Rosenberg (EAR): validade fatorial e consistência interna. Psico-USF, São Paulo, v. 15, n. 3, p. 395-403, set./dez. 2010.

VAZ, A. F. Jogos, esportes: desafios para a educação física escolar. Cadernos de Formação RBCE, Porto Alegre, v. 1, n. 2, p. 96-106, mar. 2010.

VITIMA de racismo Angelo Assumpção diz que foi impedido de falar sobre o caso pela CBG. Rio de Janeiro, 30/07/2015. 2017. Disponível em: <https://oglobo.globo.com/esportes/vitima-de-racismo-angelo-assumpcao-diz-que-foiimpedido-de-falar-sobre-caso-pela-cbg-17010792>. Acesso em: 30 ago. 2017.

Recebido em: 09/03/2018

Revisado em: 10/06/2018

Aprovado em: 25/07/2018

Endereço para correspondência:

thiago.emedeiros@yahoo.com.br

Thiago Emannuel Medeiros

Universidade do Estado de Santa Catarina

Departamento de Educação Física.

Rua Pascoal Simone, 358

Coqueiros

88080-350 - Florianópolis, SC - Brasil 